\title{
Certolizumab pegol: an evidence-based review of its place in the treatment of Crohn's disease
}

\author{
Andrea Cassinotti, Sandro Ardizzone, Gabriele Bianchi Porro \\ Department of Clinical Science, Chair of Gastroenterology, "L. Sacco" University Hospital, Milan, Italy
}

\begin{abstract}
Introduction: Crohn's disease (CD) is a chronic inflammatory bowel disease characterized by a relapsing/remitting course with transmural inflammation of potentially any section of the digestive tract. Certolizumab pegol (CZP) is a pegylated Fc-free Fab' fragment of a humanized anti-TNF-alfa monoclonal antibody that is in development for clinical use in CD.

Aims: To review the available data with CZP in CD, to investigate its possible place in therapy.

Evidence review: Available studies suggest that CZP has the potential to achieve and maintain clinical response and remission in moderate to severe CD, and to improve quality of life compared with placebo. Further studies with CZP are also ongoing.

Place in therapy: Although only suggested by currently available studies, successive clinical practice and further ongoing trials may confirm a positive role for CZP as a new anti-TNF treatment in CD. The impact on clinical management or on resources cannot be estimated until the results from all phase III clinical trials are available and the price is determined.
\end{abstract}

Core Evidence. 2007;2(3):209-224

Key words: anti-TNF, biological therapy, certolizumab pegol, Crohn's disease

Core evidence place in therapy summary for certolizumab pegol in Crohn's disease

\begin{tabular}{|c|c|c|}
\hline Outcome measure & Evidence & Implications \\
\hline \multicolumn{3}{|l|}{ Patient-oriented evidence } \\
\hline Easier subcutaneous use & Substantial & $\begin{array}{l}\text { Possible better patient compliance and minor costs compared with intravenous } \\
\text { anti-TNF agents }\end{array}$ \\
\hline $\begin{array}{l}\text { Improvement in intestinal symptoms (clinical } \\
\text { response) in active disease }\end{array}$ & Moderate & $\begin{array}{l}\text { More data on induction requested by FDA. No direct comparison with steroids } \\
\text { or infliximab or adalimumab }\end{array}$ \\
\hline Total regression of symptoms (clinical remission) & Moderate & $\begin{array}{l}\text { More data on induction requested by FDA. No direct comparison with steroids } \\
\text { or infliximab or adalimumab }\end{array}$ \\
\hline Improvement in quality of life & Substantial & Beneficial effects on patient-perceived quality of life \\
\hline Steroid-sparing effect & Not available & Study ongoing \\
\hline \multicolumn{3}{|l|}{ Disease-oriented evidence } \\
\hline Mucosal healing & Not available & Study ongoing \\
\hline Lower incidence of side effects & Substantial & Long-term data required \\
\hline Efficacy in fistulizing disease & Not available & Further studies required \\
\hline Improvement of natural history of the disease & Not available & Further studies required \\
\hline \multicolumn{3}{|l|}{ Economic evidence } \\
\hline Cost effectiveness & Not available & Evidence required, even if theoretically positive \\
\hline
\end{tabular}




\section{Scope, aims, and objectives}

Certolizumab pegol (CZP, Cimzia ${ }^{\mathrm{TM}}$ ), previously named CDP870, is being developed by UCB for clinical use in Crohn's disease (CD). It is a polyethylene glycol (PEG)-conjugated, humanized, antigen-binding fragment (Fab') of an anti-tumor necrosis factor alfa (TNF-alfa) monoclonal antibody (mAb) to be administered subcutaneously.

An extensive phase III trial program to explore CZP in moderate to severe CD has been developed. The purpose of this article is to review the available data on CZP to investigate its possible role in clinical management of CD, which is important at this stage in its development to highlight some critical issues for its optimal use. Results obtained with other agents are briefly reviewed for comparative purposes.

\section{Methods}

Electronic searches were conducted using PubMed, Scopus, and clinical trial registries (http://www.clinicaltrials.gov) databases from the earliest records to September 2007. The search terms used were "certolizumab pegol," "CDP870," "therapy," "biologicals," "inflammatory bowel disease," and "Crohn's disease". Reference lists of all relevant articles were searched for further studies. Of the identified studies only articles published in the English language were selected. Abstracts and other material from meetings were also included in the analysis.

The levels of evidence identified from the literature searches are summarized in Table 1. Twenty-six full papers and no abstracts were identified in the initial search. Records were manually reviewed and eight full-text papers were excluded because of their redundancy as low-quality review of data available elsewhere. After an additional search, a total of 21 full papers and 22 abstracts were identified. Among these, five full papers and 11 abstracts were considered for final analysis concerning clinical efficacy and safety of CZP in CD.

Table 1 | Evidence base included in the review

\begin{tabular}{|lcc|}
\hline Category & \multicolumn{2}{c|}{ Number of records } \\
\cline { 2 - 3 } & Full papers & Abstracts \\
\hline Initial search & 26 & 0 \\
$\quad$ records excluded & 8 & 0 \\
$\quad$ records included & 18 & 0 \\
Additional studies identified & 3 & 22 \\
Level 1 clinical evidence & 1 & 0 \\
(systematic review, meta analysis) & & 11 \\
Level 2 clinical evidence (RCT) & 4 & 0 \\
Level $\geq 3$ clinical evidence & 0 & 0 \\
Economic evidence & 0 & 11 \\
Total records included & 5 & \\
\hline For definition of levels of evidence, see Editorial Information on inside back cover or on \\
Core Evidence website. & & \\
RCT, randomized controlled trial. & & \\
\hline
\end{tabular}

\section{Disease overview}

Crohn's disease is a chronic inflammatory bowel disease (IBD) characterized by a relapsing/remitting course with transmural inflammation of potentially any section of the digestive tract, leading to various intestinal (internal and external fistulas, intestinal strictures, abdominal and perianal abscesses) and extraintestinal manifestations (Podolski 2002). Its incidence is five out of 100000 people and its prevalence is estimated to be 30-50 out of 100000 people in Western countries. The disease represents an important public health problem as it tends to affect young people and have a chronic course affecting quality of life, social activities, and working abilities (Shanahan 2002).

While the etiology remains unknown, the understanding of the molecular mediators and mechanisms of tissue injury have greatly advanced (Ardizzone \& Bianchi Porro 2005). The disease has been suggested to develop in a genetically predisposed subject due to a disregulated immune response to unknown antigens (probably environmental or infective, including endogenous microflora), resulting in continuous immune-mediated inflammation (Ardizzone \& Bianchi Porro 2002a).

In the absence of a well-defined etiology, current treatment protocols are aimed at modulating, by various approaches, the complex inflammatory events leading to intestinal injury (Travis et al. 2006). However, the treatments currently available cannot be considered curative and, even today, up to $70 \%$ of patients undergo surgery due to complications of the disease. Moreover, an important subgroup of patients fail to show a significant benefit from conventional treatments, thus delineating the particular scenario of refractory $C D$ and the need for novel therapeutic strategies.

The proinflammatory cytokine TNF-alfa is a key mediator of inflammation associated with CD (Breese \& McDonald 1995). Its biological activities include the induction of proinflammatory cytokines such as interleukin (IL)-1 and IL-6, activation of neutrophils, and enhancement of leucocyte migration (Papadakis \& Targan 2000). Increased levels of TNF-alfa are found in diseased areas of the bowel wall, and in the blood and stools of patients with CD, compared with normal controls (Braegger et al. 1992; Murch et al. 1993; Reinecker et al. 1993).

\section{Current therapy options}

Current therapeutic management of $C D$ is usually defined as a "step-up" strategy, based on the use of drugs with a gradually increasing strength of action, according to disease extension, severity (mild, moderate, or severe), activity (induction vs maintenance therapy), disease pattern (inflammatory, penetrating-fistulizing, or stricturing), response to current or prior medications, and the presence of complications (Ardizzone \& Bianchi Porro 2005). Available treatments aim to induce remission, prevent relapses, improve quality of life, and address complications. Conventional drugs used in CD consist of aminosalicylates, corticosteroids, immunosuppressors (azathioprine, 6-mercaptopurine, 
methotrexate) and immunomodulators such as infliximab and, more recently, adalimumab.

Aminosalicylates are considered first-line therapy for mild to moderate CD, although their efficacy is controversial and data from recent reviews and meta analyses suggest their substantial inefficacy in CD (Cammà et al. 1997).

Corticosteroids are indicated for moderate to severe active CD or for patients who do not respond to first-line therapy. They induce remission in $48 \%$ of patients and improve symptoms in another $32 \%$ within 30 days of treatment start, whereas $20 \%$ of patients are resistant from onset (Munkholm et al. 1994). Although corticosteroids can suppress active inflammation in the acute setting, they are ineffective maintenance agents, and long-term use is associated with important side effects (such as osteoporosis, hypertension, diabetes mellitus, and ocular complications) and high relapse rates, often complicated by the occurrence of steroid dependency or refractoriness. Indeed, 1 year after starting corticosteroids, only $32 \%$ of CD patients are corticosteroid-free without surgery, which underscores the importance of maintenance therapy after a corticosteroid-induced remission (Faubion et al. 2001).

The thiopurines azathioprine and 6-mercaptopurine are effective maintenance agents, including in steroid-dependent patients (Caprilli et al. 2005a), with $42 \%$ of patients treated with azathioprine achieving remission at 15 months after induction with glucocorticoids compared with only $7 \%$ in the placebo group (Candy et al. 1995). However, these drugs act slowly (Present et al. 1980) and they are limited by potentially important adverse events, with $10-20 \%$ of patients being intolerant of them.

Methotrexate can be used as an induction agent for steroiddependent CD (remission rate $39.4 \%$ at 12 weeks) and for maintenance of remission after successful induction $(65 \%$ of patients relapse-free after 40 weeks), and it is an alternative for patients not responding to or intolerant to azathioprine or 6-mercaptopurine. However, methotrexate has the disadvantages of potential myelosuppression, hepatotoxicity, and teratogenic and abortigenic effects (Feagan et al. 1995, 2000).

Advances in the understanding of IBD pathogenesis have permitted the development of agents (referred to as "biological therapy") directed against rational therapeutic targets, including TNF-alfa antagonists such as infliximab and adalimumab (Caprilli et al. 2005b). Infliximab was the first anti-TNF agent approved for use in the management of $C D$, while adalimumab was approved by the Food and Drug Administration (FDA) in the US and by the Committee for Medicinal Products for Human Use (CHMP) in Europe in 2007. Infliximab is an intravenously administered chimeric mAb of the immunoglobulin G-1 (IgG1) subclass and is comprised of $75 \%$ human and $25 \%$ mouse sequences. Adalimumab is a subcutaneously administered, recombinant, fully human IgG1 mAb specific for TNF-alfa. Both drugs can be used for induction and maintenance of remission in patients with moderate to severe active, steroid-refractory luminal $C D$, or with fistulizing $C D$ who are refractory to conventional medical therapy
(Ardizzone et al. 2002b; Rutgeerts et al. 2004; Plosker \& LysengWilliamson 2007).

In most clinical trials exploring biological therapies in CD, efficacy has been evaluated using the Crohn's Disease Activity Index (CDAI), a score that combines both clinical and laboratory parameters, where clinical remission is defined as a CDAI $\leq 150$, and clinical response can be defined either as a reduction in the score of at least 70 ("70-point response") or 100 points ("100-point response") compared with the basal value of $>150$, with the latter being a more rigorous clinical result (Best et al. 1976).

In the study by Targan et al. (1997) $81 \%$ of patients responded (70-point response) to infliximab $5 \mathrm{mg} / \mathrm{kg}$ versus $17 \%$ for placebo at 4 weeks. A total of $33 \%$ of patients treated with all infliximab doses $(5,10$, or $20 \mathrm{mg} / \mathrm{kg})$ achieved remission versus $4 \%$ for placebo. In the large $(n=573)$ ACCENT I trial, $58 \%$ of patients responded to a single open-label infusion of infliximab $5 \mathrm{mg} / \mathrm{kg}$ by week 2 (Hanauer et al. 2002). At week 30, remission was maintained in $39 \%$ and $45 \%$ of patients treated with infliximab $5 \mathrm{mg} / \mathrm{kg}$ and $10 \mathrm{mg} / \mathrm{kg}$, respectively, compared with $21 \%$ of placebo recipients. However, about $30 \%$ of patients with refractory $C D$ have consistently been found to be infliximabresistant. In addition, not all other patients are full responders. Moreover, there is a loss of response to repeated infliximab infusions in a proportion of patients, which seems unrelated to the immunogenicity associated with the chimeric antibody. Finally, the cost of biological therapies is high.

Regarding adalimumab, its clinical efficacy and safety in patients with moderate to severe $C D$ has been demonstrated in four randomized, double-blind trials (CLASSIC-I, GAIN, CHARM, and CLASSIC-II). The 4-week CLASSIC-I trial tested three induction regimens of adalimumab versus placebo in 299 anti-TNF-naïve patients: 1) adalimumab $40 \mathrm{mg}$ at week 0 and $20 \mathrm{mg}$ at week 2 (40 mg/20 mg); 2) adalimumab $80 \mathrm{mg}$ at week 0 and $40 \mathrm{mg}$ at week 2 (80 mg/40 mg); 3) adalimumab $160 \mathrm{mg}$ at week 0 and $80 \mathrm{mg}$ at week 2 (160 mg/80 mg); or 4) placebo at weeks 0 and 2 . Adalimumab $80 \mathrm{mg} / 40 \mathrm{mg}$ or $160 \mathrm{mg} / 80 \mathrm{mg}$ was significantly more effective than placebo for induction of remission in these patients ( $24 \%$ vs $36 \%$ vs $12 \%$ at week $4 ; P=0.004$ ) (Hanauer et al. 2006). Adalimumab $160 \mathrm{mg} / 80 \mathrm{mg}$ was also more effective than placebo for induction of remission in the 4-week GAIN study in 325 patients who developed loss of responsiveness or intolerance to infliximab, where a remission rate of $21 \%$ was obtained at week 4 compared with $7 \%$ of placebo recipients $(P<0.001)$ (Rutgeerts et al. 2006). In the 56-week CHARM study, 854 patients were treated with adalimumab $80 \mathrm{mg} / 40 \mathrm{mg}$ in a 4-week open-label induction phase, where 58\% achieved remission at week 4 . These responders $(n=499)$ were then randomized to 1 year of maintenance therapy with adalimumab $40 \mathrm{mg}$ weekly or every other week, or placebo through week 56 . Higher remission rates were achieved with adalimumab every other week or weekly compared with placebo (36\% vs $41 \%$ vs $12 \%$, respectively, at week $56 ; P<0.001)$. Moreover, the two regimens of adalimumab were more effective than placebo in complete fistula closure (Colombel et al. 2007a). Finally, in 
CLASSIC-II, an extension of the CLASSIC-I trial, 55 patients in remission after a short course of adalimumab (40 $\mathrm{mg}$ at week 0 and 2) rerandomized to adalimumab $40 \mathrm{mg}$ every other week or weekly showed higher remission rates after 56 weeks than patients receiving placebo $(79 \%$ vs $83 \%$ vs $44 \% ; P<0.05)$ (Sandborn et al. 2007a).

\section{Unmet needs}

The limitation in both efficacy and safety encountered with the current medical approaches for $C D$ continues to drive the search for better therapeutic agents.

The therapeutic use of murine mAbs in humans is considerably limited by issues relating to immunogenicity. Chimeric antibodies such as infliximab can induce strong human antichimeric antibody (HACA) responses when administered to patients; these are referred to as antibodies to infliximab (ATI) and have been detected in $30-61 \%$ of patients treated with episodic infliximab treatment compared with 7-10\% of patients on a scheduled infliximab regimen (Baert et al. 2003; Farrell et al. 2003; Hanauer et al. 2004). In the treatment of chronic disorders (e.g. CD), where large or repeat doses of $\mathrm{mAbs}$ may be required, the potential consequences of HACA are a shortening of the mAb half-life in serum and a secondary loss of efficacy, in addition to potential infusion reactions, kidney damage, and serum sickness. In addition, humanized antibodies such as adalimumab can induce the development of antibodies called human antihuman antibodies (HAHA), thus underlining that despite the reduction in the mouse content of these mAbs, this is not a guarantee of a completely nonimmunogenic molecule.

The induction of ATI with infliximab can be reduced by concomitant administration of corticosteroids and immunosuppressant agents such as methotrexate or azathioprine. ATI incidence was $46 \%$ in patients receiving concomitant immunosuppressors compared with $73 \%$ if no concomitant immunosuppressors were given $(P<0.001)$ in a recent study (Vermeire et al. 2007). However, this is at the expense of related side effects, including a potential long-term risk of malignancies such as lymphoma, and an increased risk of infections.

It has been shown that treatment with infliximab may also be associated with occurrence of antibodies to double-stranded DNA (23-34\%) and antinuclear antibodies (45-56\%); symptoms of drug-induced lupus, however, occurred in only $0.2 \%$ of patients (Hanauer et al. 2002; Sands et al. 2004).

Besides immunogenicity, several other factors limit the use of infliximab, such as toxicity, cardiovascular and autoimmune disorders, demyelinating disease, and a $1 \%$ mortality rate, reported in 500 patients after a median follow-up of 17 (range, 0-48) months (Colombel et al. 2004). Moreover, an infusion reaction rate of $16-21 \%$ has been reported (with headache, dizziness, nausea, injection-site irritation, flushing, chest pain, dyspnea, or pruritus) compared with $9-17 \%$ with placebo, and infections in $30-34 \%$ of patients (most frequently respiratory and urinary tract infections, including opportunistic infections and active tuberculosis), compared with 27-37\% with placebo (Ljung et al. 2004; Blonski \& Lichtenstein 2006a).

In the effort to improve anti-TNF treatment, new agents targeting this cytokine have been designed and tested in clinical trials. It is generally believed, but not yet proven, that the amount of murine protein present in monoclonal antibodies is directly related to immunogenicity. Significant progresses have been made in the development of humanized forms of anti-TNF compounds in order to improve this aspect (Table 2); these include adalimumab, CZP, CDP571, etanercept, and onercept.

Table 2 | Pharmacologic characteristics of anti-TNF agents (adapted from Weir et al. 2006)

\begin{tabular}{|c|c|c|c|c|}
\hline Characteristic & Certolizumab pegol & Etanercept & Adalimumab & Infliximab \\
\hline Structure & $\begin{array}{l}\text { Pegylated humanized Fab' } \\
\text { fragment of an anti-TNF-alfa } \\
\text { mAb. No Fc region }\end{array}$ & $\begin{array}{l}\text { Fusion protein: human TNF-R } \\
\text { p75 monomer fused with FC } \\
\text { domain of human IgG1 }\end{array}$ & $\begin{array}{l}\text { Recombinant human } \\
\text { IgF1 mAb }\end{array}$ & $\begin{array}{l}\text { Chimeric mouse-human } \\
\text { lgG1 mAb }\end{array}$ \\
\hline Conjugate & PEG & No & No & No \\
\hline Route of delivery & s.c. injection & s.c. injection & s.c. injection & i.v. infusion \\
\hline Half-life (days) & 14 & 4.8 & $14-19$ & $8-10$ \\
\hline Dosing frequency & Monthly & Twice weekly & Injection every 2 weeks & Infusion every 8 weeks \\
\hline Manufacture & Microbial fermentation & $\begin{array}{l}\text { Expression in mammalian } \\
\text { cell lines }\end{array}$ & $\begin{array}{l}\text { Expression in mammalian } \\
\text { cell lines }\end{array}$ & $\begin{array}{l}\text { Expression in mammalian } \\
\text { cell lines }\end{array}$ \\
\hline TNF-alfa binding & Soluble and membrane-bound & Soluble and membrane-bound & Soluble and membrane-bound & $\begin{array}{l}\text { Soluble, membrane-, and } \\
\text { receptor-bound }\end{array}$ \\
\hline Affinity for TNF-alfa $\left(K_{D}, p M\right)$ & 89.3 & NA & 157.4 & 227.2 \\
\hline Potency $\left(\mathrm{IC}_{90}, \mathrm{ng} / \mathrm{mL}\right)$ & 0.4 & NA & 6 & 5 \\
\hline Apoptosis & No & Yes? & Yes & Yes \\
\hline ADCC/CDC & No & Yes & Yes & Yes \\
\hline
\end{tabular}


Besides searching for new effective compounds, recent studies have focused on possible development of different cultural approaches to the disease; this is the case for the previously referred to "top-down" strategy, in the effort to improve the clinical results achieved with the classical step-up approach and with the potential ability to alter the natural history of $C D$. To date, anti-TNF therapy has been reserved for patients with refractory disease who have not responded to corticosteroids and immunosuppressants (Lowenberg et al. 2006). Recently, the more aggressive top-down therapeutic strategy was used early in the disease course to find out whether this would lead to better clinical outcomes, as suggested by a preliminary study, available only in abstract form (Hommes et al. 2006). While top-down therapy appears to have many advantages, its potential for immunogenicity, loss of response, cost, and long-term safety issues may somewhat limit its wholesale application. Instead, a "risk-stratified" top-down approach may emerge, where those at risk for worse outcomes are initially treated with more aggressive therapy. At this point, however, the tools to identify such high-risk patients remain crude (Orlando et al. 2005).

Controlled trials offer the best means to establish clinical efficacy and to identify the most common side effects of a therapy. The risk of a hurried and uncritical reception of positive results-however modest-should be considered for any CD drug, but even more so for compounds where economic and safety implications are important. This situation has already occurred with previous compounds, including a successful drug such as infliximab, although we can now benefit from a longer period of clinical knowledge and use. On the other hand, it is not time to make such a judgment with CZP too, or other new anti-TNF-alfa agents. In this paper we would like to stress some truths that the turbulent "ideal world" of clinical trials may forget. Firstly, it should be remembered that "statistical significance" does not always reflect "clinical significance." Second, in designing a clinical efficacy protocol, the need to establish adequate therapeutic targets instead of creating any surrogates that emphasise otherwise modest results should be underlined. Although the use of response rate may be more efficient in determining drug efficacy, it does appear to be particularly susceptible to a high placebo effect; in this regard, remission rates may be a more appropriate and clinically meaningful primary endpoint (Winter et al. 2006). Third, it is worthwhile pointing out that CDAl, on which most randomized clinical trial results of $C D$ have been based, is not a perfect instrument, being influenced by many confounding factors, and therefore does not always reflect the real correlation between symptoms and disease activity. Other rigorous activity indexes such as mucosal healing, or other important patient-oriented parameters such as quality of life, should be evaluated in future studies, although there is much debate about their accuracy.

In conclusion, it is our opinion that the main targets for any therapy to be considered indicative of some efficacy in trials in CD should be the induction and the maintenance of complete remission that is at least clinically and, possibly, endoscopically proven (instead of variably defined partial responses), and the prevention of adverse events in order to improve patient compliance, complication rate, and the need for surgery.

\section{Clinical evidence with certolizumab pegol in Crohn's disease}

\section{Structure and pharmacokinetics}

Since the inception of targeted antibody technologies in the mid-1960s, immunotherapy has undergone a number of developments to improve disease treatment and reduce immunogenicity (Weir et al. 2006).

One of the most recent advances in antibody-based therapies is the use of antibody fragments, including Fab' fragments, as used in CZP. CZP is a PEG-conjugated, humanized, Fc-free Fab' fragment of an anti-TNF-alfa mAb (Blick \& Curran 2007).

As with infliximab, adalimumab, and CDP571, the initial stage of development of CZP consisted on the selection of an hybridoma (designated HTNF40) secreting a high-affinity, potent murine IgG1 anti-TNF-alfa antibody. CZP was then obtained by grafting the short hypervariable complementarity-determining regions (CDRs) derived from HTNF40 onto an otherwise virtually human IgG Fab' fragment (Weir et al. 2002). The CZP-Fab' fragment can be considered to have $98 \%$ human germline residues.

CZP differs from other anti-TNF agents in being univalent, while adalimumab, etanercept, and infliximab are bivalent. A recent study available only in abstract form suggests the pathologic importance of this property. This stoichiometric study of binding and complex formation with TNF by anti-TNF agents shows that the bivalent antibodies adalimumab and infliximab crosslink TNF trimers by binding to monomers in different trimers, while the univalent structure of CZP does not permit it. The large immune complexes formed by infliximab or adalimumab with TNF trimers can cause degranulation and superoxide production by neutrophils, thus inducing inflammation, while CZP does not appear to cause these effects (Henry et al. 2007).

CZP exhibited a linear pharmacokinetic profile after administration of a single subcutaneous 20,60 , or $200 \mathrm{mg}$ dose in six healthy volunteers in a randomized, double-blind, doseescalating study (Baker et al. 2006). Bioavailability of subcutaneous CZP is high (estimated to be 100\%) (Fossati \& Nesbitt 2005a,b). In healthy volunteers, the apparent volume of distribution was $45 \mathrm{~mL} / \mathrm{kg}$, and clearance was $0.17 \mathrm{~mL} / \mathrm{h}$ per $\mathrm{kg}$ (modeled data) (Baker et al. 2006).

The small size of Fab' fragments is generally accompanied by a reduction in half-life in comparison to that of their parent Ig; the IgG $\mathrm{mAb}$ has a half-life of 104 hours in rats, while the Fab' fragment has a half-life of only 22.7 hours (Fossati \& Nesbitt $2005 a, b)$. In CZP, this short half-life is overcome by conjugation with two molecules of PEG, prolonging in-vivo half-lives in rats to 45.8 hours, while in humans the elimination half-life is 192 hours (i.e. about 2 weeks), comparable with that of full-length humanized antibodies (Zalipsky 1995). The prolonged in-vivo halflife is thought to be a result of reduced proteolysis (by avoidance of cellular clearance) or excretion (by avoidance of renal clearance as a result of the polymer increasing the apparent size of the 
molecule to above the glomerular filtration limit) (Rose-John \& Schooltink 2003). In addition to increasing the half-life, pegylation offers other important potential advantages, including improved thermal and mechanical stability, improved solubility in aqueous solution, and improved bioavailability. The latter is $80-100 \%$ in models after subcutaneous dosing. Overall, these pharmacokinetic properties provide suitability for both intravenous and subcutaneous administration (Baker et al. 2006). Subcutaneous administration has potential advantages over the intravenous route, in terms of convenience and safety owing to a lack of infusion reactions.

Fab' fragments have further benefits compared with full antibodies in terms of ease of production. Because of the necessity for glycosylation of the Fc portion of whole antibodies, the currently marketed anti-TNF agents infliximab and adalimumab are produced by expression in mammalian cell lines. However, bulk production via mammalian cell lines is slow and there is the potential for low product titers and production of heterogeneous antibodies (Weir et al. 2002). Fab' fragments such as CZP do not require glycosylation. Moreover, CZP is synthesized by fed-batch fermentation in Escherichia coli. These aspects ensure a relatively simple, rapid (fermentation time of 3 days compared with 2-3 weeks), and reproducible process, yielding a consistent and reliable supply of Fab' fragments.

\section{Biologic properties and pharmacodynamics}

A difference among the available anti-TNF agents is related to the ability of the IgG1 monoclonal antibodies infliximab, adalimumab, and etanercept to fix complement. This is not the case for CZP (Fossati \& Nesbitt 2005c). Since it lacks the Fc portion of the antibody, CZP only exerts its activity through binding to soluble and membrane-bound TNF-alfa, and cannot bind to cell-surface receptors for antibodies; consequently, complement fixation and cell lysis do not occur. This results in a lack of the potentially detrimental effects of complement-dependent cytotoxicity (CDC) and antibody-dependent T-cell-mediated cytotoxicity (ADCC) (Chapman 2002).

Another difference relates to the pharmacodynamic features of CZP compared with other anti-TNF agents. Although all available anti-TNF agents are capable of neutralizing soluble as well as transmembrane forms of TNF-alfa, CZP has been shown to have higher affinity and potency to TNF-alfa than infliximab and adalimumab in vitro (Nesbitt \& Henry 2004). A recent study showed how CZP is more potent than all other anti-TNF agents in inhibiting monocyte release of TNF-alfa and IL-1-beta induced by lipopolysaccharide; in general, the ability to inhibit other cytokines (IL-10, IL-12, granulocyte colony-stimulating factor, IL-1RA, MIP1-beta, TNF-RI, TNF-RII) has been observed for CZP as well as for infliximab, adalimumab, and etanercept (Fossati et al. 2007).

Until now, neutralization of TNF-alfa alone has been considered insufficient for clinical efficacy in patients with $C D$, while the capacity to destroy TNF-alfa-expressing cells was thought to be required. Infliximab, adalimumab, etanercept, and onercept, but not CZP, are capable of inducing apoptosis of TNF-alfa- expressing T cells and monocytes (Fossati \& Nesbitt 2005c). Apoptosis is a distinct mode of cell death and represents a crucial regulatory mechanism to remove redundant cells in many physiologic events. CD is indeed characterized by mucosal T-cell proliferation that exceeds T-cell apoptosis (Ina et al. 1999). Infliximab has been shown to restore the inappropriate T-cell accumulation by induction of apoptosis (Ten Hove et al. 2002). An interesting debate has emerged regarding the importance of T-cell apoptosis to the clinical efficacy of CZP. Both CZP and infliximab are effective in $C D$, yet while infliximab has been shown to induce apoptosis, CZP lacks this property. Although in-vitro studies showed the ability of infliximab to induce apoptosis in activated $\mathrm{T}$ cells, the in-vivo clinical relevance of these findings remain unclear. A recent in-vivo study using single photon emission computed tomography (SPECT) with real visualization of apoptosis has demonstrated that apoptosis in the intestine is induced by chimeric anti-TNF treatment in both experimental colitis and in human CD, where it can be predictive of efficacy of anti-TNF treatment (Van den Brande et al. 2007). Despite these data, onercept, although not effective in CD, is capable of inducing apoptosis. It remains unclear, therefore, which of the properties of TNF-alfa antagonists confers clinical efficacy in CD (Chang \& Lichtenstein 2006) and the specific role of apoptosis is yet to be elucidated.

\section{Phase /l trials}

Level 2 evidence from fully published studies investigating the efficacy and safety of CZP is available, including placebocontrolled studies (Winter et al. 2004; Schreiber et al. 2005a).

Administration of CZP by the intravenous route was first investigated in a phase II trial by Winter et al. (2004). In this randomized, single-dose, double-blind, placebo-controlled, parallel-group, multicenter study involving 92 adult patients with moderate to severe CD (CDAI 220-450), CZP 5, 10, or $20 \mathrm{mg} / \mathrm{kg}$, or placebo was administered over a 12-week period (two patients received $1.25 \mathrm{mg} / \mathrm{kg}$ ). These doses are higher than in normal practice for subcutaneous delivery. The primary endpoint was the percentage of patients achieving the 100-point response or remission (CDAI $\leq 150)$ at week 4 in the intention-to-treat (ITT) population. The percentage of patients achieving the primary endpoint was comparable across all treatment groups $(56.0 \%$, $60.0 \%, 58.8 \%$, and $47.8 \%$ for placebo, CZP 5,10 , and $20 \mathrm{mg} / \mathrm{kg}$, respectively). While no statistically significant difference in clinical response was observed between CZP and placebo, clinical benefit in terms of remission was demonstrated. A single intravenous infusion of CZP $10 \mathrm{mg} / \mathrm{kg}$ induced remission at 2 weeks in a significantly greater number of patients $(47.1 \%)$ than placebo $(16 \%, P=0.041)$ and was generally well tolerated. The remission was ongoing at week 4 in CZP recipients, but at week 8 and 12 it was similar to the placebo group. It is worthy of mention that a high placebo response rate was observed, and this may partially explain the poor induction ability.

A successive phase II trial (Schreiber at al. 2005a) explored the subcutaneous use of CZP in a multicenter, randomized, doubleblind, placebo-controlled, dose-ranging study. It was initially 
designed for a sample size of 260 to reach a power of $83 \%$ to detect a difference of $23 \%$ between the treatment and placebo groups. The study assumed a placebo response rate of $12 \%$ for achieving their primary endpoints.

A total of 292 patients with moderate to severe CD (CDAI 220-450) was included and randomized to receive either placebo or subcutaneous certolizumab $100 \mathrm{mg}(\mathrm{n}=74), 200 \mathrm{mg}(\mathrm{n}=72)$, and $400 \mathrm{mg}(\mathrm{n}=73)$ administered at 0,4 , and 8 weeks. The primary endpoint was the percentage of patients achieving a clinical response at week 12, defined as a decrease in CDAI score of at least 100 points or remission (CDAl $\leq 150)$. The percentage of patients showing a clinical response at weeks 2, 4, 6, 8, and 10, was a secondary efficacy variable, as was the percentage of patients in clinical remission $(\mathrm{CDAl} \leq 150)$ at weeks 2, 4, 6, 8, 10, and 12.

Two hundred and seven patients completed the study. In the placebo group $24.7 \%$ of patients withdrew from the study by week 12 , compared with $29.7 \%, 20.8 \%$, and $27.4 \%$ for the CZP $100 \mathrm{mg}, 200 \mathrm{mg}$, and $400 \mathrm{mg}$ treatment groups, respectively; most of the withdrawals were a consequence of disease progression (see Safety and tolerability for the adverse event rates in this trial).
At all doses, CZP was able to reduce C-reactive protein (CRP) concentrations at week 2 more efficiently than placebo. These data support the antiinflammatory effect of CZP. The CZP doses of $200 \mathrm{mg}$ and $400 \mathrm{mg}$ were more able to induce this biologic response over the 12-week study period.

The onset of treatment clinical effect was rapid (Fig. 1a,b). Indeed, at week 2 all doses of CZP induced a clinical response producing a statistically significant benefit compared with placebo $(29.7 \%$ for CZP $100 \mathrm{mg}, 30.6 \%$ for CZP $200 \mathrm{mg}$, and 33.3\% for CZP $400 \mathrm{mg}$ vs $15.1 \%$ for placebo). CZP $400 \mathrm{mg}$ and $200 \mathrm{mg}$ were also superior to placebo in clinical response at week 4, while CZP $400 \mathrm{mg}$ and $100 \mathrm{mg}$ doses were better than placebo at week 8 . Only the $400 \mathrm{mg}$ dosage maintained a better benefit than placebo at week $10(52.8 \%$ vs $30.1 \% ; P=0.006)$, when the highest response rate was observed. However, at the predefined primary endpoint time (week 12), there were no significant differences between the treatments (36.5\% for CZP $100 \mathrm{mg}, 36.1 \%$ for CZP $200 \mathrm{mg}$, and 44.4\% for CZP $400 \mathrm{mg}$ ) and placebo group (35.6\%). Concerning the remission rates, all CZP doses induced statistically higher percentage of remission than placebo at week 4; CZP $400 \mathrm{mg}$ and $100 \mathrm{mg}$ were also better than placebo at week 8 and, only for CZP $400 \mathrm{mg}$, also at week 10. However, at week 12, this benefit was not confirmed, and the difference

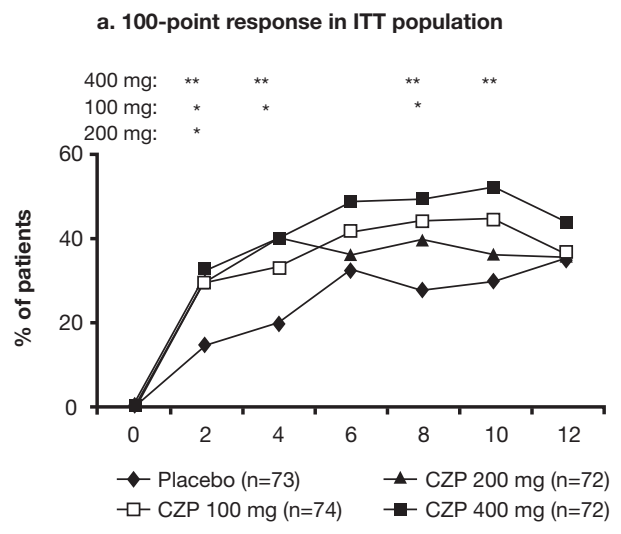

b. Remission rate in ITT population

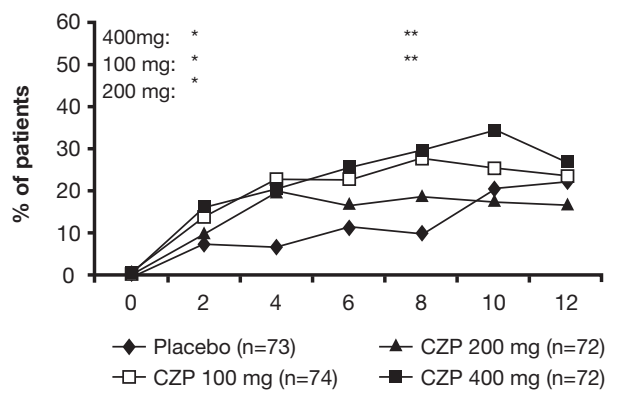

c. 100-point response in high CRP stratum

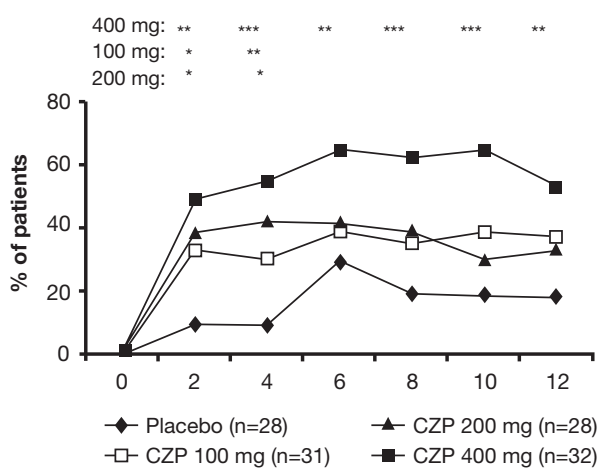

d. Remission rate in high CRP stratum

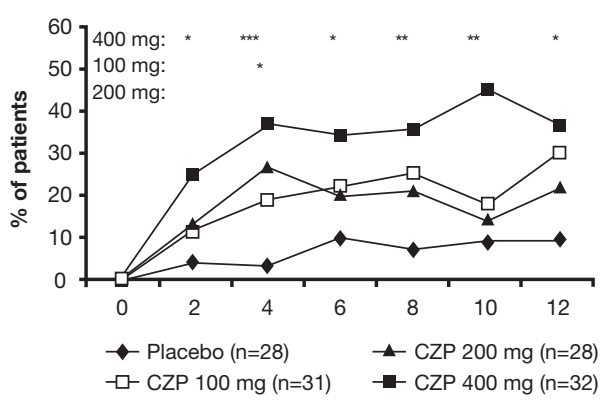

Fig. 1 | Clinical efficacy of subcutaneous CZP (adapted from Schreiber et al. 2005a with permission from Elsevier). ${ }^{\star} P<0.05$; ${ }^{\star \star} P<0.01$; ${ }^{* * *} P<0.001$ vs placebo. CRP, C-reactive protein; CZP, Certolizumab pegol ITT. intent-to-treat 
between the CZP- and placebo-treated groups did not reach statistical significance $(27 \%$ for CZP $100 \mathrm{mg}, 19.4 \%$ for CZP $200 \mathrm{mg}$, and $26.4 \%$ for CZP $400 \mathrm{mg}$ vs $23.3 \%$ for placebo). The authors found no difference in clinical response to CZP between the patients who were taking concomitant immunosuppressants and those who were not.

Both phase II trials failed to satisfy their primary endpoints, suggesting a certain inability to induce remission. A review of the data and debate ensued, when potential bias and confounding elements that may have influenced the results emerged.

Firstly, an overall response rate of $36.6 \%$ and a remission rate of $23.3 \%$ were observed at week 12 in the placebo group. This unexpected high placebo response rate may have contributed to the apparent failure of the study agent. High placebo response rate is common in randomized clinical trials in IBD. A meta analysis of placebo-controlled, randomized clinical trials reported that placebo rates for clinical remission ranged from $0 \%$ to $50 \%$ and response rates ranged from $0 \%$ to $46 \%$ (Su et al. 2004). The duration of studies was the most important predictor of placebo remission and response. Given the 12-week length of the Schreiber et al. (2005a) study, one would expect a foreseeable rate of spontaneous response or remission. One would also expect that extension of the study may have resulted in an additional increase in the placebo response rate (Oikonomou \& Shen 2006).

Second, it is worthy of mention that although all patients had symptoms indicating moderate to severe CD according to the CDAl, only $41 \%$ had baseline serum CRP levels $\geq 10 \mathrm{mg} / \mathrm{L}$. Patients with low baseline CRP levels showed a particularly high placebo response rate at week 12 (46.7\%), compared with $38.1 \%$, 38.6\%, and $37.5 \%$ in the $100 \mathrm{mg}, 200 \mathrm{mg}$, and $400 \mathrm{mg}$ CZP groups. The placebo response decreased with increasing baseline CRP levels. These data may further explain the unsatisfactory overall clinical effect, because patients with low CRP levels may have problems not necessarily amenable to antiinflammatory treatment.

In addition to these explanatory observations, a post-hoc analysis not delineated in the original study was included and confirmed the relationship between efficacy and CRP level. This analysis was performed by stratification of patients according to CRP levels $\geq$ or $<10 \mathrm{mg} / \mathrm{L}$. It was observed that in patients with a higher baseline CRP level ( $n=119 ; 41 \%$ of patients as mentioned above), treatment with CZP $400 \mathrm{mg}$ resulted in a statistically significant benefit at all time points throughout the 12-week study in terms of both clinical response and remission rate (Fig. 1c,d). Specifically, a clinical response or remission was achieved in $53.1 \%$ of patients with a baseline CRP $\geq 10 \mathrm{mg} / \mathrm{L}$ when treated with CZP $400 \mathrm{mg}$, compared with $17.9 \%$ of patients who received placebo $(P=0.005)$.

\section{Phase III trials}

Level 2 evidence from fully published studies investigating the efficacy and safety of CZP is available, including placebocontrolled studies (Sandborn et al. 2007b; Schreiber et al. 2007b).
The PRECiSE (Pegylated Antibody Fragment Evaluation in Crohn's Disease: Safety and Efficacy) program, composed of four studies (PRECiSE 1, 2, 3, and 4), represents a large, comprehensive development program for CZP in CD, including 1328 patients, with a planned follow-up phase of up to 5 years.

In PRECiSE 2, a total of 668 patients with moderate to severe active $C D$ received open-label induction therapy with subcutaneous CZP $400 \mathrm{mg}$ given at 0, 2, and 4 weeks (Schreiber et al. 2005b, 2007b). At week 6, patients who responded to induction therapy (with at least a 100-point response) were randomized in a double-blind phase to a maintenance regimen with either CZP 400 mg every 4 weeks or placebo through week 24 , with follow-up through week 26 . Upon enrollment, patients were stratified for CRP level ( $<$ or $\geq 10 \mathrm{mg} / \mathrm{L}$ ), baseline steroid and immunosuppressant use (Fig. 2). The primary endpoint was a clinical response at week 26 in patients with a baseline CRP level $\geq 10 \mathrm{mg} / \mathrm{L}$; secondary endpoints included response at week 26 and remission at week 26 in the ITT population, and remission in the group with a baseline CRP level of at least $10 \mathrm{mg} / \mathrm{L}$.
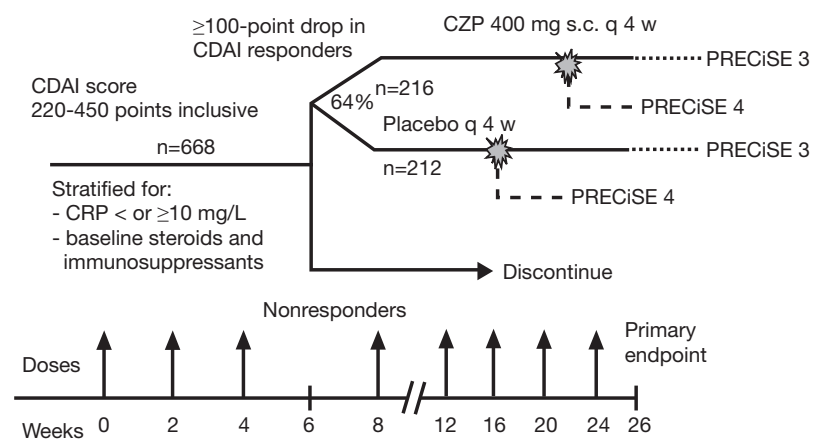

$$
\begin{array}{ccc}
\text { CZP open-label } & \begin{array}{c}
\text { Identify } \\
\text { induction phase } \\
\text { responders } \\
\text { Randomize 1:1 }
\end{array} & \begin{array}{c}
\text { Randomized, } \\
\text { double-blind, } \\
\text { maintenance phase }
\end{array}
\end{array}
$$

Fig. 2 | PRECiSE 2 study design (adapted from Schreiber et al. 2007b). CDAI, Crohn's Disease Activity Index; CRP, C-reactive protein; CZP, certolizumab pegol; s.c., subcutaneous; q 4 w, every 4 weeks

At week 6, CZP induced remission in 43\% $(n=289)$ and clinical response in $64 \%(n=428)$ of patients among the overall population; clinical response was $63.4 \%$ among those in the higher CRP group. Compared to the data from the phase II trials described above, these results showed similar positive effects irrespective of baseline CRP levels.

At week 26, the 100-point clinical response rate and remission rate $(C D A I \leq 150)$ were significantly higher following treatment with CZP compared with placebo, again irrespective of CRP levels. In particular, in the ITT population 63\% maintained response at week 26 , compared with $36 \%$ in the placebo group $(P<0.001)$ and the remission rate was $48 \%$ in CZP recipients versus $29 \%$ of 
patients who received maintenance with placebo $(P<0.001)$ (Fig. 3). Among those with high baseline CRP levels, response at week 26 was $62 \%$ compared with $34 \%$ in the placebo group $(P<0.001)$, while the corresponding remission rate was $42 \%$ compared with 26\% $(P=0.01)$. Prior and concomitant use of immunosuppressants did not result in higher efficacy.

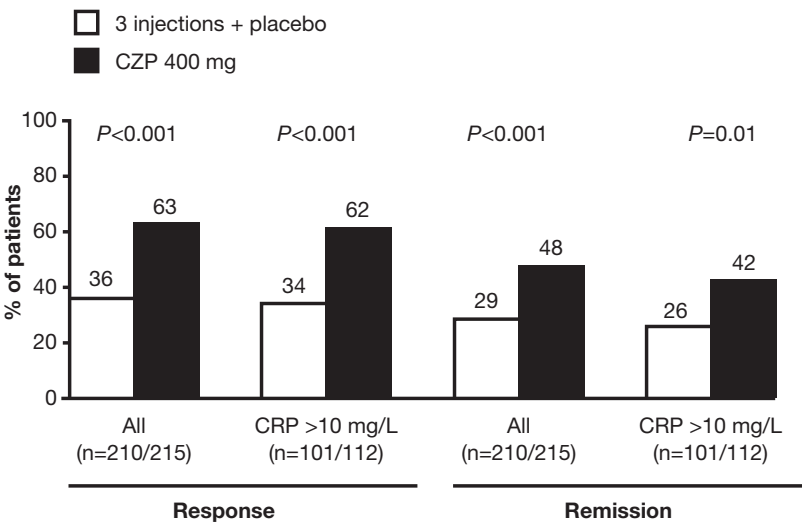

Fig. 3 | PRECiSE 2: response and remission rate at week 26 (Schreiber et al. 2007b). CRP, C-reactive protein; CZP, certolizumab pegol

Patients were included only according to their CDAl at baseline, indicating moderate to severe disease irrespective of prior response to other drugs, including infliximab (primary failures to infliximab were excluded, secondary failures were not). No data are currently available from CZP studies in the specific subset of patients previously treated with infliximab or not. This is required to define the clinical role of CZP. Evidence-based data are necessary to establish, for example, if CZP should be considered a first-line drug (top-down strategy) or as treatment in resistant patients. Regarding some of these aspects, subanalyses from PRECiSE 2 have shown that CZP was effective in most patients regardless of prior use of infliximab or concomitant immunosuppressant or glucocorticoid treatment (Colombel et al. 2007c). Among the 668 baseline patients, $24.3 \%$ had received prior infliximab, 34.9\% were receiving immunosuppressants, and $40.5 \%$ were receiving glucocorticoids. Patients previously treated with infliximab had slightly longer disease duration than infliximab-naïve patients and a higher incidence of penetrating disease; this pattern did not appear for concomitant medications. Following the induction phase (CZP at weeks 0, 2, and 4), responders were defined at week 6 , and the clinical response rates evaluated. At this time point, response rates were similar in all subgroups, and this was maintained through week 26. Compared with an overall response of $64.1 \%$ at week 6 , the corresponding rates according to concomitant or prior drugs were as follows: $68.4 \%$ in infliximab-naïve patients, $53.9 \%$ in patients receiving prior infliximab, $66.3 \%$ in patients on immunosuppressants, $62.7 \%$ in patients not on immunosuppressants, $62.9 \%$ in patients on glucocorticoids, and $64.8 \%$ in patients not on glucocorticoids. At week 26 , response rates were significantly greater with CZP than placebo in all cohorts, irrespective of prior infliximab use: overall $62.8 \%$ versus $36.2 \% \quad(P<0.01)$, infliximab-naïve $68.7 \%$ vs $39.6 \%$ $(P<0.001)$, prior infliximab use $44.2 \%$ vs $25.5 \% \quad(P=0.018)$, on immuno-suppressants $61 \%$ vs $33 \%(P<0.001)$, not on immunosuppressants $64 . \%$ vs $39 \%(P<0.001)$, on glucocorticoids $57 \%$ vs $32 \%(P<0.002), 66 \%$ vs $39 \%(P<0.001)$ not on glucocorticoids. $A$ similar pattern was observed for remission at week 26 , achieved in $52.8 \%$ vs $33.3 \%$ of infliximab-naïve patients $(P<0.001)$ and in $32.7 \%$ versus $13.7 \%$ of prior infliximab-treated patients $(P=0.008)$. In the overall population, remission at week 26 was achieved in $47.9 \%$ vs $28.6 \%$ of patients in the CZP and placebo groups, respectively.

These data suggest that CZP is effective irrespective of concomitant treatment with immunosuppressants or glucocorticoids; the slightly better results in the infliximab-naïve group than in prior infliximab users can be influenced by the different baseline characteristics of the included patients, such as a longer disease duration in prior infliximab users indicating a more resistant patient group. However, good results, although not dramatic, are documented in both groups. A specific trial, named WELCOME (26-Week Open-Label Trial Evaluating the Clinical Benefit and Tolerability of Certolizumab Pegol Induction and Maintenance in Patients Suffering from Crohn's Disease with Prior Loss of Response or Intolerance to Infliximab), is currently ongoing to further explore the efficacy of CZP in infliximabrefractory or intolerant $C D$ patients.

Interesting results from a further phase III trial (PRECiSE 1) have also been presented (Sandborn et al. 2007b). The primary outcomes were met, with benefits of CZP treatment over placebo, regardless of baseline CRP levels. The PRECiSE 1 design is very interesting and can give robust results. It is the first reported phase III, double-blind, placebo-controlled study of an anti-TNF agent extending to 26 weeks, without an unblinded induction phase to preselect responders as the eligible patients to be randomized at study baseline (Fig. 4).

In PRECiSE 1, a total of 660 patients with moderate to severe CD (CDAl 220-450) were included and randomized to receive either subcutaneous CZP $400 \mathrm{mg}(\mathrm{n}=331)$ or placebo, at weeks $0,2,4$ and then every 4 weeks through to week 24 . Patients were primarily stratified according to baseline CRP levels $(<$ or $\geq 10 \mathrm{mg} / \mathrm{L}$ ) and immunosuppressant/corticosteroid use. The primary endpoints were the percentage of patients in the CRP $\geq 10 \mathrm{mg} / \mathrm{L}$ stratum achieving a 100-point clinical response at week 6 , and at week 6 and 26 combined. Secondary endpoints included 70-point response, remission (CDAI $\leq 150)$, and median CRP levels in the ITT population and in the high CRP stratum.

Among patients with a baseline CRP level $\geq 10 \mathrm{mg} / \mathrm{L}$, a significantly greater proportion of patients treated with CZP achieved a 100-point response at week 6 (37\% vs $26 \%$; $P<0.05)$ and at week 6 and 26 combined (22\% vs $12 \% ; P<0.05)$, compared with placebo. Similar significant efficacy for CZP over 


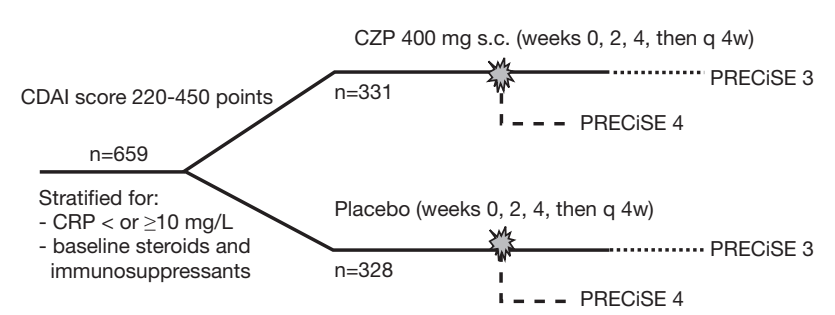

Coprimary endpoint Week 6

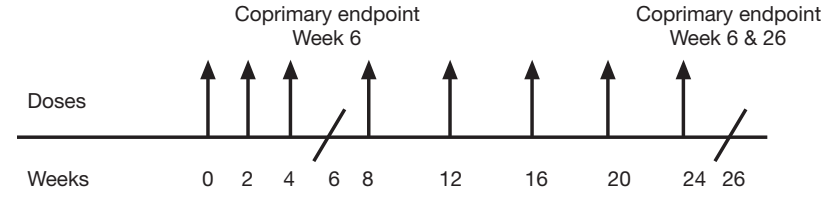

Fig. 4 | PRECiSE 1 study design (Sandborn et al. 2007b). CDAl, Crohn's Disease Activity Index; CRP, C-reactive protein; CZP, certolizumab pegol; s.c., subcutaneous; q 4 w, every 4 weeks

placebo was demonstrated for the 70-point response in a further post-hoc analysis at the same time points. In addition, the remission rate at week 4 was higher in the CZP group compared with placebo ( $20 \%$ vs $10 \%$; $P<0.05$ ), while a nonsignificant trend in favor of CZP was observed at week 6 and at the combined week 6 and 26 time point (Table 3). Among the ITT population, the 100 -point response was significantly in favour of CZP at week 4 (29\% vs $22 \%$; $P<0.05)$, at week $6(35 \%$ vs $27 \% ; P<0.05)$ and at week 6 and 26 combined (23\% vs $16 \% ; P<0.05)$. On the other hand, the remission rate was better in the CZP group only at week $4(20 \%$ vs $11 \% ; P<0.01)$, while at week 6 and week 6 and 26

Table 3 | PRECiSE 1: outcomes with CZP for the ITT population and the CRP $>10 \mathrm{mg} / \mathrm{L}$ stratum (adapted from Crofskey 2006)

\begin{tabular}{|c|c|c|c|c|}
\hline & \multicolumn{2}{|c|}{ ITT population } & \multicolumn{2}{|c|}{ High CRP stratum } \\
\hline & $\begin{array}{l}\text { Placebo } \\
(n=328)\end{array}$ & $\begin{array}{c}\text { CZP } \\
(n=331)\end{array}$ & $\begin{array}{r}\text { Placebo } \\
(n=156)\end{array}$ & $\begin{array}{c}\text { CZP } \\
(n=146)\end{array}$ \\
\hline \multicolumn{5}{|c|}{100 -point response $(\%)$} \\
\hline Week 4 & 21.8 & $28.7^{a}$ & 20.6 & $32.9^{\mathrm{a}}$ \\
\hline Week 6 & 26.8 & $35.2^{\mathrm{a}}$ & 26.0 & $37.2^{\mathrm{a}}$ \\
\hline Week 6 and 26 & 16.0 & $23.1^{\mathrm{a}}$ & 12.3 & $21.5^{\mathrm{a}}$ \\
\hline \multicolumn{5}{|c|}{ 70-point response (\%) } \\
\hline Week 4 & 33.7 & $44.0^{\mathrm{b}}$ & 30.3 & $50.3^{b}$ \\
\hline Week 6 & 37.8 & $46.2^{\mathrm{a}}$ & 33.1 & $46.9^{\mathrm{a}}$ \\
\hline Week 6 and 26 & 22.5 & $32.0^{\mathrm{b}}$ & 14.9 & $29.2^{\mathrm{b}}$ \\
\hline \multicolumn{5}{|l|}{ Remission } \\
\hline Week 4 & 11.3 & $19.5^{\mathrm{b}}$ & 9.7 & 20.1 \\
\hline Week 6 & 17.2 & 21.6 & 16.9 & 21.9 \\
\hline Week 6 and 26 & 9.8 & 14.4 & 8.4 & 13.1 \\
\hline $\begin{array}{l}\text { a } P<0.05 \text { vs placeb } \\
{ }^{b} P<0.01 \text { vs placeb } \\
\text { CRP, C-reactive pr }\end{array}$ & olizuma & $T T$, in & treat & \\
\hline
\end{tabular}

combined the drug showed no significant difference $(P=0.17)$ with placebo (Table 3). Of interest, significantly more CZP recipients achieved remission at week $26(29.5 \%$ vs $18.3 \%$; $P<0.05)$.

\section{Safety and tolerability}

In both phase II trials the prevalence of adverse events, mostly mild to moderate in intensity, was similar in both placebo and active treatment groups $(62.5-69.9 \%$ for placebo versus $63.2-73 \%$ for CZP; $P$ value not reported). No deaths were observed, nor were any cases of lymphoma, lupus, tuberculosis, or opportunistic infections recorded, or anaphylaxis observed (Blonski \& Lichtenstein 2006b).

In the study by Winter et al. (2004) a total of 164 adverse events were reported by 43 patients who received CZP. The most common adverse events included headache $(n=35)$, exacerbation of CD (7), urinary tract infection (5), unspecified abdominal pain (4), fever (4), and nausea (4). Of note, all urinary tract infections occurred in the patients treated with active drug. Overall, nine patients experienced a total of 11 serious adverse events during the study period: $2 \%$ in the placebo group compared with $10.3 \%$ in the CZP group, for all doses. The majority of serious events were gastrointestinal. In the placebo group they included exacerbation of CD (1) and erythematous rash (1). Serious adverse events reported with CZP included aggravated CD (3), abdominal pain (2), intestinal obstruction (2), perianal abscess (1), and drug overdose (1). Eight of the 11 serious events were considered to be unrelated to study drug, while the remaining three events were considered possibly related (erythematous rash in one patient given placebo; aggravated $C D$ and perianal abscess in CZP recipients).

In the study by Schreiber et al. (2005a) the most frequent adverse events with CZP included headache (13.2\% vs $16.4 \%$ for placebo), aggravation of CD (11.9\% vs $13.7 \%)$, nausea (11.4\% vs $5.5 \%)$, and nasopharyngitis $(9.1 \%$ vs $4.1 \%)$. Others included dizziness (excluding vertigo) (6.4\% vs $4.1 \%$ ), unspecified abdominal pain (5.9\% vs $5.5 \%$ ), arthralgia (5.9\% vs $2.7 \%$ ), pharyngolaryngeal pain (5\% vs $5.5 \%$ ), and fever (5\% vs $4.1 \%$ ). Infection was observed in $26.5 \%$ of CZP-treated patients versus $23.3 \%$ of the placebo group during the double-blind period and in $14.2 \%$ versus $13.7 \%$ during the safety follow-up period. The following serious adverse events were reported, in decreasing order of frequency: worsening $C D$, rectal hemorrhage, abdominal mass, reduced visual acuity, pyrexia, vomiting and paralytic ileus, breast hyperplasia, ankle ulcer, thrombocytopenia, and perianal abscess.

Whereas the study by Winter et al. (2004) did not report any infusion reactions with the intravenous route, Schreiber and colleagues $(2005 b)$ reported a higher incidence of injection-site adverse events (burning, erythema, inflammation, pain, or rash) among patients treated with active drug (5\%) compared with placebo $(2.7 \%)$; the most common reaction occurring within 30 min of administration was injection site burning.

A combined analysis of tolerability data from PRECiSE 1 and PRECiSE 2 has also been presented; this post-hoc review 
included a total of 1328 patients (Schreiber et al. 2007a). Data from the double-blind phases of both trials showed that CZP was generally well tolerated. The incidence of adverse events was comparable in the CZP and placebo groups. Most adverse events were of mild to moderate severity; overall, the most common adverse events in patients receiving CZP were headache, nasopharyngitis (in both studies), abdominal pain (PRECiSE 1), and cough (PRECiSE 2). The most frequent infections were nasopharyngitis, urinary tract infections, and upper respiratory tract infections. The incidence of serious adverse events in PRECISE 1 was $10.3 \%$ in the CZP group and $7 \%$ in the placebo group. Corresponding values during PRECiSE 2 were $6 \%$ and $7 \%$. No cases of lupus were reported in either trial. The incidence of malignancy was infrequent and similar between treatment groups in the PRECiSE 1 trial (two patients in each group: one metastatic lung cancer in a 22-year-old male previously treated with multiple infliximab infusions and azathioprine, methotrexate, and corticosteroids, and one rectal carcinoma in a 44-year-old man, in the CZP group; one Hodgkin's lymphoma in a 33-year-old man, and one cervical carcinoma in situ in a 21-year-old woman for placebo). No malignancies were reported in PRECiSE 2. In PRECISE 2, one case of tuberculosis, which responded well to antituberculosis therapy, was observed. Injection reactions were uncommon and less frequent with CZP than placebo (3\% vs $15 \%$ in PRECiSE 2; $3 \%$ vs $14 \%$ in PRECiSE 1). One death occurred in the CZP group of each study (one acute myocardial infarction in the already cited 22-year-old male with hypertensive heart disease and metastatic lung cancer 10 months after withdrawal from the study; one accidental fentanyl overdose in PRECiSE 2); neither was considered treatment-related.

A combined interim analysis on long-term safety in PRECiSE 3 and 4 , available only in abstract form, showed no new safety signals of concern (Colombel et al. 2007d).

These data seem to indicate a good safety profile of CZP, with a lower adverse-event rate than other anti-TNF agents. It is, however, worth nothing that the reported incidences of adverse events from PRECiSE 1 and 2 refer to the double-blind phasetherefore the open-label section of PRECiSE 2 with 6 weeks of first exposure to CZP would have been excluded. It is interesting to note that the higher rates of serious adverse events for CZP were seen in PRECISE 1, which also had a randomized induction phase.

\section{Immunogenicity}

It is well known that the administration of any protein, including those that are fully human, may be associated with the development of antibodies (Fefferman \& Farrell 2005). The mechanisms underlying a protein's immunogenicity are complex and poorly understood and go far beyond the species from which a therapeutic protein is derived. Humanization of therapeutic antibodies diminishes but does not abolish the risk of antidrug antibodies (Van Assche et al. 2006).

Anti-CZP antibodies levels were low or undetectable using enzyme-linked immunosorbent assay (ELISA) after a single intravenous infusion $(1,5$, or $20 \mathrm{mg} / \mathrm{kg}$ ) in patients with rheumatoid arthritis, while antibodies were detected in all treatment groups after a treatment cycle, with lower incidence in patients treated with higher doses (Choy et al. 2002).

The study by Schreiber et al. (2005b) showed that $12.3 \%$ of patients receiving CZP $400 \mathrm{mg}$ had at least one positive result for anti-CZP antibodies. However, no decrease in efficacy was seen, since the proportion of responders patients at week 12 was similar in antibody-positive and -negative patients, with $44 \%$ of patients responding in both subgroups. The study has not provided data on the correlation between concomitant corticosteroids or immunomodulators use and the development of antibodies (only $37.5 \%$ of the patients from CZP $400 \mathrm{mg}$ group were on concomitant immunomodulators at baseline). In PRECiSE 1 and 2 the occurrence of anti-CZP antibodies was reported in $8 \%$ and $9 \%$ of patients, respectively (Sandborn et al. 2007b; Schreiber et al. 2007b).

Moreover, anti-infliximab antibodies did not cross-react with CZP in 20 patients with CD (Vetterlein et al. 2006), where anti-CZP antibody levels were undetectable, thus suggesting that CZP can be used in patients who develop an antibody response to infliximab. On the other hand, antibodies to CZP did not crossreact with adalimumab, etanercept, or infliximab in 22 patients with $\mathrm{CD}$, thus suggesting that patients initially treated with CZP could subsequently receive other anti-TNF agents with no risk of cross-reactivity (Vetterlein et al. 2007).

Autoantibody production for antinuclear antibodies was reported at week 26 in $2 \%$ of CZP recipients versus $1 \%$ of placebo recipients in PRECISE 1, and was reported in $8 \%$ vs $1 \%$ in PRECISE 2; corresponding values for antidoublestranded DNA antibodies were $1 \%$ for patients receiving CZP versus $1 \%$ for patients receiving placebo in PRECiSE 1 and $1 \%$ versus $0.6 \%$ in PRECiSE 2 (Sandborn et al. 2007b; Schreiber et al. 2007b).

Preliminary data from PRECiSE 3 and 4, available only in abstract form, show positivity to antinuclear antibodies in $14.1 \%$ and $3 \%$, respectively, and antidouble-stranded DNA in $3.2 \%$ and $2.7 \%$, respectively in PRECiSE 3 and 4 (Colombel et al. 2007d).

\section{Quality of life}

Marginal improvement in quality of life $(P=0.05)$ was observed in the CZP $400 \mathrm{mg}$ group compared with placebo in the phase II trial by Schreiber et al. (2005a). Clinically meaningful improvements in Inflammatory Bowel Disease Questionnaire (IBD-Q) total score (16-point increase) were seen in $52.8 \%$ of patients in the CZP $400 \mathrm{mg}$ group at week 2 (vs $32.9 \%$ in placebo group), increasing to $66.7 \%$ at week 12 (vs $50.7 \%$ in placebo group).

In PRECiSE 1, 42\% of patients had an IBD-Q response at week 26 , compared with $33 \%$ in placebo recipients $(P=0.01)$, while the corresponding values during PRECiSE 2 were $60 \%$ and $43 \%$ $(P<0.001)$ at week 26 (Sandborn et al. 2007b; Schreiber et al. 2007b). 
Some subanalyses from PRECiSE 1 and 2, available in abstract form, have further focused on quality of life in CZP-treated patients. Firstly, CZP improved health-related quality of life in $C D$, assessed through the IBD-Q at week 6, 16 and 26. Both after the induction phase (week 6) and at the end of the maintenance phase (week 26), quality of life improved in CZP recipients at levels that are indicative of remission (from a mean of 122.6 points at week 0 to a mean of 174.8 points at week 6 and a mean of 175.7 points at week 26) and in all the four domains of the IBD-Q (Table 4). Moreover, at week 26 a significantly higher IBD-Q response (increase in total score from baseline $>16$ points) in the CZP group than placebo was observed (Feagan et al. 2007b). CZP has been shown to improve work productivity and the ability to perform daily activities, as assessed through the work productivity and activity impairment (WPAl) questionnaire, at week 0, 6, 16, and 26, regarding all four dimensions and impairment scores (absenteeism, presenteeism, overall work impairment, and daily activities impairment) (Feagan et al. 2007a,c).

Table 4 | Effect of treatment with CZP on the IBD-Q score changes from baseline (Feagan et al. 2007b)

\begin{tabular}{|c|c|c|c|c|c|}
\hline \multirow[t]{4}{*}{ IBD-Q domain } & \multicolumn{5}{|c|}{ Mean IBD-Q score } \\
\hline & \multirow{2}{*}{\multicolumn{2}{|c|}{$\frac{\text { Induction phase }}{\text { CZP }}$}} & \multicolumn{2}{|c|}{ Maintenance phase } & \multirow[b]{3}{*}{$P$ value } \\
\hline & & & Placebo & CZP & \\
\hline & Week 0 & Week 6 & Week 26 & Week 26 & \\
\hline Total score & 122.6 & 174.8 & 167.9 & 175.7 & 0.001 \\
\hline $\begin{array}{l}\text { Bowel } \\
\text { symptoms }\end{array}$ & 38.6 & 54.7 & 51.8 & 54.7 & 0.001 \\
\hline $\begin{array}{l}\text { Systemic } \\
\text { symptoms }\end{array}$ & 15.7 & 24.7 & 23.9 & 25.3 & 0.001 \\
\hline $\begin{array}{l}\text { Emotional } \\
\text { function }\end{array}$ & 47.1 & 65.4 & 62.6 & 65.6 & 0.002 \\
\hline $\begin{array}{l}\text { Social } \\
\text { function }\end{array}$ & 21.2 & 30.0 & 29.5 & 30.1 & 0.048 \\
\hline
\end{tabular}

\section{Certolizumab pegol in top-down algorithms}

At present, no trials have directly investigated the use of CZP as first-line treatment of newly diagnosed CD patients. Only indirect data are available from post-hoc subanalyses of PRECiSE 2 (Schreiber et al. 2006; Colombel et al. 2007b). In the subanalysis by Schreiber et al. (2006), the rates of response and remission at week 26 in the overall ITT population were explored according to disease duration at baseline. Overall, CZP was superior to placebo for maintenance at week 26, irrespective of disease duration. Induction rates were similar across all groups regardless of disease duration. The proportion of patients in response and remission on maintenance therapy at week 26 was inversely correlated with disease duration (Table 5). In recently diagnosed patients (time from diagnosis $<1$ year), CZP maintained a response in $89.5 \%$ of the subgroup and a remission in $68.4 \%$ vs $37.1 \%$ in the placebo groups. These data seem to suggest a benefit from
Table 5 | PRECiSE 2 subanalysis: response and remission rates according to treatment and disease duration at week 26 (adapted from Schreiber et al. 2006)

\begin{tabular}{|c|c|c|c|c|}
\hline \multirow{2}{*}{$\begin{array}{l}\text { Time from } \\
\text { diagnosis }\end{array}$} & \multicolumn{2}{|c|}{ Response } & \multicolumn{2}{|c|}{ Remission } \\
\hline & Placebo, \% (n) & CZP, \% (n) & Placebo, \% (n) & CZP, \% (n) \\
\hline Any & $36.2(210)$ & $62.8^{a}(215)$ & $28.6(210)$ & $47.9^{\mathrm{a}}(215)$ \\
\hline$<1$ year & $37.1(35)$ & $89.5^{\mathrm{b}}(19)$ & $37.1(35)$ & $68.4^{\mathrm{C}}(19)$ \\
\hline $1-2$ years & $50.0(22)$ & $75.0(20)$ & $36.4(22)$ & $55.0(20)$ \\
\hline $2-5$ years & $36.4(55)$ & $62.2^{c}(45)$ & $29.1(55)$ & $46.7(45)$ \\
\hline$\geq 5$ years & $32.7(98)$ & $57.3^{a}(131)$ & $23.5(98)$ & $44.3^{a}(131)$ \\
\hline $\begin{array}{l}\text { a } P<0.001 \text { vs } \\
{ }^{\mathrm{b}} P<0.01 \text { vs } \\
{ }^{\mathrm{c}} P<0.05 \text { vs } P \\
\text { CZP, certoliz }\end{array}$ & $\begin{array}{l}\text { po. } \\
\text { pegol. }\end{array}$ & & & \\
\hline
\end{tabular}

early intervention with CZP for the long-term maintenance of response and remission in patients with active CD.

Specific trials primarily designed to confirm these results are needed, in addition to the need to demonstrate a real diseasemodifying benefit.

\section{Ongoing studies}

PRECiSE 3 and 4 are both long-term (up to 5 years) open-label trials assessing the longer-term efficacy, safety, and tolerability of CZP in patients from PRECISE 1 and PRECiSE 2, and are currently ongoing. Briefly, at week 26 , completers of PRECiSE 1 and 2 who participate in PRECiSE 3 receive CZP $400 \mathrm{mg}$ every 4 weeks for up to 5 years (Fig. 5). In PRECiSE 4, patients who relapsed after week 2 in PRECiSE 1 (Fig. 4) or after randomization in PRECiSE 2 (Fig. 2), receive reinduction with CZP 400 mg (three doses at week 0, 2, and 4) followed by maintenance dosing every 4 weeks (Fig. 6). Relapse was defined as a CDAl increase of $>70$ points or absolute CDAI $>350$. For patients who relapsed

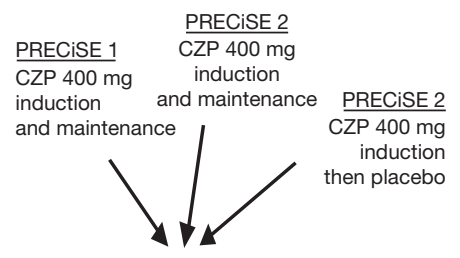

PRECISE 3 CZP $400 \mathrm{mg}$

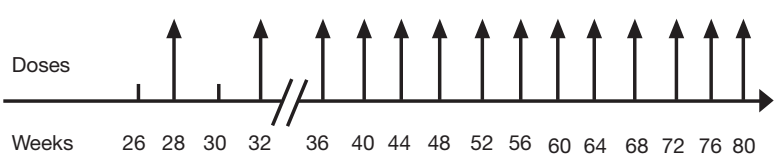

Fig. 5 | PRECiSE 3 study design (Schreiber et al. 2007c). CZP, certolizumab pegol 
despite maintenance therapy with CZP, reinduction constitutes a single additional dose at week 2, compared with the PRECiSE 1 and 2 regimen. PRECiSE 3 and 4 use the Harvey-Bradshaw Index for assessment of efficacy. Preliminary results from these two trials have recently been presented as an interim analysis in abstract form, showing the drug's ability to maintain long-term remission and to reinduce clinical response in "withdrawal" patients (Sandborn et al 2007c; Schreiber et al. 2007c).

Enrollment is also currently ongoing in the phase IIlb, multicenter clinical trial, WELCOME, designed to examine the effects of CZP in patients failing or intolerant to infliximab. In addition, the MUSIC study (Mucosal Study in Crohn's disease) will investigate the impact of CZP on endoscopic and mucosal healing, and the multicenter, randomized, placebo-controlled, phase IIlb CONCISE trial (Corticosteroid-sparing Effect of Certolizumab Pegol in Patients with Moderately Severe Crohn's Disease who are currently in remission with corticosteroid treatment) will examine the corticosteroid-sparing effect of CZP in CD.

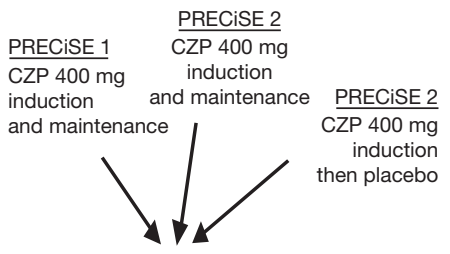

PRECISE 4 CZP $400 \mathrm{mg}$

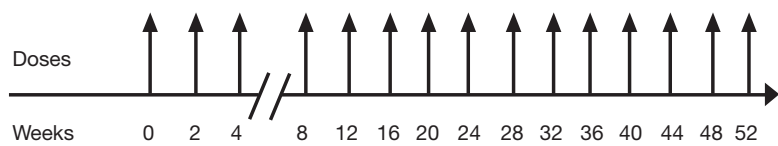

Fig. 6 | PRECiSE 4 study design (Schreiber et al. 2007c). CZP, certolizumab pegol

\section{Economic evidence}

At present, economic evidence comparing the use of CZP with other drugs is not available. Using its proprietary low-cost $E$. coli technology to produce Fab' fragments, the developer has declared that it will be able to lower the manufacturing costs of CZP by 10 - to 20 -fold compared with antibodies conventionally produced in mammalian cell culture, although, on the other hand, pegylation may be costly. However, the price of CZP has not yet been determined.

Until results from ongoing clinical trials are available and the price is determined, an estimate of the potential impact on patients and healthcare systems cannot be made. As CZP may be indicated for moderately affected as well as severely affected patients, the patient group may be larger than that for infliximab and may have a greater impact on costs, although this is very speculative. CZP is delivered as a subcutaneous injection; this may lead to some savings in staff time and associated costs.

\section{Patient group/population}

It is necessary to await results from currently ongoing trials that, in addition to those available from available studies, will definitively investigate the efficacy and safety profile of CZP in all the possible clinical scenarios in CD.

Data from PRECiSE 1-4 may suggest a role for CZP in the classical scenario of corticosteroid use, i.e. induction of remission in moderately to severely active $\mathrm{CD}$, and its successive long-term maintenance. Moreover, data from WELCOME could suggest a role for CZP in refractory CD similar to that of infliximab, or a possible place as salvage therapy in patients refractory or intolerant to this drug.

No data are available for fistulizing disease or for extraintestinal manifestations.

\section{Dosage, administration, and formulations}

Official dosage recommendations are not yet available. In clinical trials CZP was delivered by subcutaneous injection (lyophilized) as a $200 \mathrm{mg}$ vial for single use in a $5 \mathrm{~mL}$ vial reconstituted with water for injection. The maximum volume that can be given by subcutaneous injection at a single injection site is $1 \mathrm{~mL}$.

The dosage of CZP that has demonstrated the better efficacy in clinical trials is $400 \mathrm{mg}$ administered subcutaneously, so two subcutaneous injections of $200 \mathrm{mg}$ are given in two different sites; suitable areas for injection are the lateral abdominal wall or upper outer thigh. The scheduled regimen was administration at week 0 , 2 , and 4 (induction phase) and then every 4 weeks from week 6 (maintenance phase), although the WELCOME study is exploring the efficacy of a more frequent (every 2 weeks) maintenance regimen. Concomitant use of immunosuppressants does not appear to be necessary.

\section{Place in therapy}

The pharmacologic characteristics of CZP are interesting and may theoretically provide a good safety and long-term efficacy profile, as well as more practical (easier subcutaneous use) and economical (easier production cycle) features. From this point of view, CZP could be a useful addition to the anti-TNF treatments of CD. Whether CZP could be useful as a rescue therapy for patients who have failed infliximab is still to be determined, and a trial specifically investigating this is currently ongoing. At present it is also difficult to suggest a role as a substitute for other anti-TNF agents in moderate to severe refractory CD because of the lack of any definitive comparative studies with infliximab or adalimumab.

The PRECiSE 1 study indicates that in patients with moderate to severe CD, induction and maintenance therapy with CZP is associated with a modest improvement in response rates, but with 
no significant improvement in remission rates; moreover, the absolute difference in the rate of response between CZP and placebo group was relatively small (Sandborn et al. 2007b). Based on these data, the question arises whether physicians will want to compromise on efficacy for the potential of better long-term safety (Rutgeerts et al. 2004). However, the results of currently available induction trials cannot be compared with trial results obtained with the other anti-TNF agents infliximab or adalimumab, since they had different design and duration, and therefore we do not know whether the findings are reproducible (Lewis 2007). Data concerning the induction efficacy of CZP differed among the double-blind PRECiSE 1 trial (35\%), the double-blind phase II trial (45\%), and the openlabel phase of the PRECiSE 2 trial (64\%) (Schreiber et al. 2005a, 2007a; Sandborn et al. 2007a). It is therefore not a surprise that the FDA has requested more data on the induction efficacy of CZP.

More interesting results concern the efficacy of CZP as a maintenance therapy when the drug has induced a response. The PRECiSE 2 trial shows that maintenance therapy with CZP is effective in patients with moderate to severe CD who had responded to open-label induction therapy with CZP (Schreiber et al. 2007b), as occurred in similarly designed trials with infliximab and adalimumab. Once again, however, a direct comparison of the maintenance results between trials is not appropriate at this time, and selection between the various anti-TNF agents should be made on the basis of comparative studies. Unfortunately, it is unlikely that such comparative trials will be conducted. Thus, the final choice of therapy will have to take into account other factors, such as costs and convenience for patients (Lewis 2007).

It is also difficult to establish a certain role for CZP as first-line treatment in moderately to severely active $C D$, unless a significant positive effect on the natural course of the disease can be demonstrated. The safety and economic profile of CZP, compared with available drugs (corticosteroids) also has to be considered in this scenario.

CZP, as well as adalimumab, is administered subcutaneously, which can be an important benefit in patients who have difficult venous access, and may avoid intravenous catheters. Self-administration may make it more difficult to monitor adherence to therapy, although it may also make patients more active participants in their own care, thus increasing compliance. Self-administration can also decrease indirect costs, such as recruitment of medical practitioners or time lost from work. What effect self-administration may have on safety is unknown.

In conclusion, CZP is very promising and deserves attention but more studies, some of them in press or already ongoing, and the subsequent clinical application of the drug will provide the real definitive evidence for its use in CD.

\section{Acknowledgments}

All authors declare they have no conflict of interest for this publication. The research was supported by a grant from Ministero dell'Istruzione e della Ricerca Scientifica (MIUR), protocol number 2004064901.

\section{References}

Ardizzone S, Bianchi Porro G. Inflammatory bowel disease: new insights into pathogenesis and treatment. J Intern Med. 2002a;252:4675-4696.

Ardizzone S, Colombo E, Maconi G, et al. Infliximab in treatment of Crohn's disease: the Milan experience. Dig Liv Dis. 2002b;34:411-418.

Ardizzone S, Bianchi Porro G. Biologic therapy for inflammatory bowel disease. Drugs. 2005;65:2253-2286.

Baert F, Norman M, Vermeire S, et al. Influence of immunogenicity on the longterm efficacy of infliximab in Crohn's disease. $N$ Engl J Med. 2003;348:601-608.

Baker M, Stringer F, Stephens P. Pharmacokinetic properties of the anti-TNF agent certolizumab pegol. Ann Rheum Dis. 2006;65(Suppl. II):175.

Best WR, Becktel JM, Singleton JW, et al. Development of a Crohn's disease activity index. National Cooperative Crohn's Disease Study. Gastroenterology. 1976;70:439-444.

Blick SKA, Curran MP. Certolizumab pegol in Crohn's disease. Biodrugs. 2007;21:195-201.

Blonski W, Lichtenstein GR. Safety of biologics in inflammatory bowel disease. Curr Treat Options Gastroenterol. 2006a;9:221-233.

Blonski W, Lichtenstein GR. Complication of biological therapy for inflammatory bowel diseases. Curr Opin Gastroenterol. 2006b;22:30-43.

Braegger CP, Nicholls S, Murch SH, Stephens S, MacDonald TT. Tumor necrosis factor alpha in stool as a marker of intestinal inflammation. Lancet. 1992;339:89-91.

Breese E, McDonald TT. TNF alpha secreting cells in normal and diseased human intestine. Adv Exp Med Biol. 1995;371:821-824.

Cammà C, Giunta M, Rosselli M, et al. Mesalamine in the maintenance treatment of Crohn's disease: a meta-analysis adjusted for confounding variables. Gastroenterology. 1997;113:1465-1473.

Candy S, Wright J, Gerber M, Adams G, Gerig M, Goodman R. A controlled double blind study of azathioprine in the management of Crohn's disease. Gut. 1995;37:674-678.

Caprilli R, Angelucci E, Cocco A, et al. Appropriateness of immunosuppressive drugs in inflammatory bowel diseases assessed by RAND method: Italian Goup for IBD (IG-IBD) position statement. Dig Liv Dis. 2005a;37:407-417.

Caprilli R, Angelucci E, Cocco A. Early or late guided missile in the treatment of Crohn's disease? Dig Liv Dis. 2005b;37:973-979.

Chang JT, Lichtenstein GR. Drug insight: antagonists of tumor-necrosis factoralpha in the treatment of inflammatory bowel disease. Nature Clin Practice Gastroenterol Hepatol. 2006;3:220-228.

Chapman AP. Pegylated antibodies and antibody fragments for improved therapy: a review. Adv Drug Deliv Rev. 2002;54:531-545.

Choy EH, Hazleman B, Smith M, et al. Efficacy of a novel pegylated humanized anti-TNF fragment (CDP870) in patients with rheumatoid arthritis: a phase II double-blinded, randomized, dose-escalating trial. Rheumatology. 2002;41:1133-1137.

Colombel JF, Loftus EV, Tremaine WJ, et al. The safety profile of infliximab in patients with Crohn's disease: the Mayo clinic experience in 500 patients. Gastroenterology. 2004;126:19-31.

Colombel JF, Sandborn WJ, Rutgeerts P, et al. Adalimumab maintenance of clinical response and remission in patients with Crohn's disease: the CHARM trial. Gastroenterology. 2007a;132:52-65.

Colombel JF, Hanauer SB, Sandborn WJ, Panes J, Schreiber S. Certolizumab pegol is effective in patients regardless of CRP level and disease duration: data from PRECiSE 2. J Crohn's Colitis. 2007b;1:8. Abstract P018.

Colombel JF, Hanauer S, Sandborn WJ, Panes J, Schreiber S. Subcutaneous certolizumab pegol is effective in patients with prior infliximab exposure or concomitant immunosuppressant or glucocorticoid treatment: data from PRECiSE 2. J Crohn's Colitis. 2007c;1:8. Abstract P019.

Colombel J, Schreiber S, Hanauer SB, et al. Long-term tolerability of subcutaneous certolizumab pegol in active Crohn's disease: results from PRECiSE 3 and 4. Gastroenterology. 2007d;132:(Suppl. 2):A503. Abstract T1267. 
Crofskey S. Certolizumab pegol a PRECiSE treatment for Crohn's disease. Inpharma. 2006;1547:7-8.

Farrell RJ, Alsahli M, Jeen YT, Falchuk KR, Peppercorn MA, Michetti P. Intravenous hydrocortisone premedication reduces antibodies to infliximab in Crohn's disease: a randomized controlled trial. Gastroenterology. 2003;124:917-924.

Faubion WA, Loftus EV, Harmsen WS, et al. The natural history of corticosteroid therapy for inflammatory bowel disease: a population-based study. Gastroenterology. 2001;123:255-260.

Feagan BG, Rochon J, Fedorak RN, et al. Methotrexate for the treatment of Crohn's disease: the North American Crohn's Disease Study Group Investigators. N Engl J Med. 1995;332:292-297.

Feagan BG, Fedorak RN, Irvine EJ, et al. A comparison of methotrexate with placebo for the maintenance of remission in Crohn's disease: North American Crohn's Disease Study Group Investigators. N Engl J Med.

\section{0;342:1627-1632.}

Feagan B, Brown M, Gerlier L, Schreiber S. Certolizumab pegol improves work productivity and the ability to perform daily activities in patients with Crohn's disease: data from PRECiSE 2. J Crohn's Colitis. 2007a;1:7. Abstract P011.

Feagan B, Coteur G, Keininger DL, Schreiber S. Certolizumab pegol $400 \mathrm{mg}$ every 4 weeks improved health-related quality of life in patients with Crohn's disease in PRECiSE 2. J Crohn's Colitis. 2007b;1:9. Abstract P020.

Feagan BG, Sandborn WJ, Brown M, et al. Confirmed benefits of work productivity and daily activities of certolizumab pegol in Crohn's disease patients: data from PRECiSE 1. Gastroenterology. 2007c;132:(Suppl. 2):A-507. Abstract T1285.

Fefferman DS, Farrell RJ. Immunogenicity of biological agents in inflammatory bowel disease. Inflamm Bowel Dis. 2005;11:497-503.

Fossati G, Nesbitt AM. In vitro complement-dependent cytotoxicity and antibody-dependent cellular cytotoxicity by the anti-TNF agents adalimumab, etanercept, infliximab and certolizumab pegol. Am J Gastroenterol. 2005a;100(Suppl.):S299.

Fossati G, Nesbitt AM. In vitro complement-dependent cytotoxicity and antibody-dependent cellular cytotoxicity by the anti-TNF agents adalimumab, etanercept, infliximab, and certolizumab pegol (CDP870). Presented at: American College of Gastroenterology 70th Annual Scientific Meeting; October 28-November 2, 2005b; Honolulu, Hawaii. Abstract 513.

Fossati G, Nesbitt A. Effect of the anti-TNF agents, adalimumab, etanercept, infliximab, and certolizumab pegol (CDP870) on the induction of apoptosis in activated peripheral blood lymphocytes and monocytes. Am J Gastroenterol. 2005c;100(Suppl. 2):A-697.

Fossati G, Brown D, Nesbitt A. Lipopolysaccharide-induced cytokine production: the effects of certolizumab pegol, etanercept, adalimumab and infliximab. $J$ Crohn's Colitis. 2007;1:43. Abstract P151.

Hanauer SB, Feagan BG, Lichtenstein GR, et al. Maintenance infliximab for Crohn's disease: the ACCENT I randomised trial. Lancet. 2002;359:1541-1549.

Hanauer SB, Wagner CL, Bala M, et al. Incidence and importance of antibody response to infliximab after maintenance or episodic treatment in Crohn's disease. Clin Gastroenterol Hepatol. 2004;2:542-553.

Hanauer SB, Sandborn WJ, Rutgeerts P, et al. Human anti-tumor necrosis factor monoclonal antibody (adalimumab) in Crohn's disease: the CLASSIC-I trial. Gastroenterology. 2006;130:323-333.

Henry AJ, Kennedy J, Fossati G, et al. Stoichiometry of binding and complex formation with TNF by certolizumab pegol, adalimumab, and infliximab and the biologic effects of these complexes. Gastroenterology. 2007;132:(Suppl. 2): A-231. Abstract S1609.

Hommes D, Baert F, van Assche G, et al. The ideal management of CD: top down versus step up strategies: a randomized controlled trial. Gastroenterology. 2006;130:A108. Abstract 749.

Ina K, Itoh J, Fukushima K, et al. Resistance of Crohn's disease T cell to multiple apoptotic signals is associated with a Bcl-2/Bax mucosal imbalance.

J Immunol. 1999;163:1081-1090.

Lewis JD. Anti-TNF antibodies for Crohn's disease - in pursuit of the perfect clinical trial. N Engl J Med. 2007;357:96-98.
Ljung T, Karlen P, Schmidt D, et al. Infliximab in inflammatory bowel disease: clinical outcome in a population based cohort from Stockholm County. Gut. 2004;53:849-853.

Lowenberg M, Peppelenbosch M, Hommes D. Biological therapy in the management of recent-onset Crohn's disease. Drugs. 2006;66:1431-1439.

Munkholm P, Langholz E, Davidsen M, Binder V. Frequency of glucocorticoid resistance and dependency in Crohn's disease. Gut. 1994;35:360-362.

Murch SH, Braegger CP, Walzer-Smith JA, MacDonald TT. Localisation of tumor necrosis factor alpha by immunohistochemistry in chronic inflammatory bowel disease. Gut. 1993;34:1705-1709.

Nesbitt AM, Henry AJ. High affinity and potency of the pegylated Fab' fragment CDP870 - a direct comparison with other anti-TNF agents. Gut. 2004;53(Suppl. VI). Abstract 47.

Oikonomou I, Shen B. Are we moving forward in the biological treatment of Crohn's disease? Time will tell. Inflamm Bowel Dis. 2006;12:147-149.

Orlando A, Colombo E, Kohn A, et al. Infliximab in the treatment of Crohn's disease: predictors of response in an Italian multicentric open study. Dig Liv Dis. 2005;37:577-583.

Papadakis KA, Targan SR. Tumor necrosis factor: biology and therapeutic inhibitors. Gastroenterology. 2000;119:1148-1157.

Plosker GL, Lyseng-Williamson KA. Adalimumab in Crohn's disease. Biodrugs. 2007;21:125-132.

Podolski DK. Inflammatory bowel disease. N Engl J Med. 2002;347:417-428. Present DH, Korelitz BI, Wisch N, Glass JL, Sachar DB, Pasternack BS. Treatment of Crohn's disease with 6-mercaptopurine. A long-term, randomized, double-blind study. N Engl J Med. 1980;302:981-987.

Reinecker HC, Steffen M, Witthoeft T, et al. Enhanced secretion of tumour necrosis factor-alpha, IL-6, and IL-1 beta by isolated lamina propria mononuclear cells from patients with ulcerative colitis and Crohn's disease. Clin Exp Immunol. 1993;94:174-181.

Rose-John S, Schooltink H. CDP-870. Curr Opin Invest Drugs. 2003;4:588-592.

Rutgeerts P, Van Assche G, Vermeire S. Optimizing anti-TNF treatment in inflammatory bowel disease. Gastroenterology. 2004;126:1593-1610.

Rutgeerts P, Sandborn WJ, Enns R, et al. Adalimumab rapidly induces clinical response and remission in patients with moderate to severe Crohn's disease who had secondary failure to infliximab therapy: results of the GAIN study. Gut. 2006;55(Suppl. V):A20. Abstract OP-G-86.

Sandborn WJ, Hanauer SB, Rutgeerts PJ, et al. Adalimumab for maintenance treatment of Crohn's disease: results of the CLASSIC II trial. Gut. 2007a;56:1232-1239.

Sandborn WJ, Feagan BG, Stoinov S, et al. Certolizumab pegol for the treatment of Crohn's disease. N Engl J Med. 2007b;357:228-238.

Sandborn WJ, Hanauer SB, Rutgeerts PJ, et al. Re-induction and maintenance therapy with subcutaneous certolizumab pegol in patients with Crohn's disease following treatment failure: PRECiSE 4 results. Gastroenterology. 2007c;132:4(Suppl. 2):A-505. Abstract T1274.

Sands BE, Anderson FH, Bernstein CN, et al. Infliximab maintenance therapy for fistulizing Crohn's disease. N Engl J Med. 2004;350:876-885.

Schreiber S, Rutgeerts $\mathrm{P}$, Fedorak $\mathrm{RN}$, et al. A randomized, placebocontrolled trial of certolizumab pegol (CDP870) for treatment of Crohn's disease. Gastroenterology. 2005a;129:807-818.

Schreiber S, Khaliq-Kareemi M, Lawrence I, et al. Certolizumab pegol, a humanised anti-TNF pegylated Fab' fragment, is safe and effective in the maintenance of response and remission following induction in active Crohn's disease: a phase III study (PRECiSE 2). Gut. 2005b;54(Suppl. VII). Abstract 82.

Schreiber S, Colombel JF, Panes J, Scholmenrich J, McColm J, Sandborn WJ. Recent-onset Crohn's disease shows higher remission rates and durability of response to treatment with subcutaneous monthly certolizumab pegol: results from an analysis of the PRECiSE 2 phase III study. Presented at: 14th United European Gastroenterology Week; October 21-25, 2006; Berlin, Germany. 
Schreiber S, Feagan BG, Hanauer SB, Rutgeerts P, Sandborn WJ. Subcutaneous certolizumab pegol is well tolerated by patients with active Crohn's disease: results from two phase III studies (PRECISE 1 and 2). $J$ Crohn's Colitis. 2007a;1:9. Abstract P021.

Schreiber S, Khaliq-Kareemi M, Lawrance IC, et al. Maintenance therapy with certolizumab pegol for Crohn's disease. N Engl J Med. 2007b;357:239-250.

Schreiber S, Hanauer SB, Feagan BG, et al. Long-term treatment with certolizumab pegol for up to 18 months in patients with active Crohn's disease: the PRECiSE 3 efficacy results. Gastroenterology. 2007c;132(Suppl. 2):A-504. Abstract T1271.

Shanahan F. Crohn's disease. Lancet. 2002;359:62-69.

Su C, Lichtenstein GR, Krok K, et al. A meta-analysis of the placebo rates of remission and response in clinical trials of active Crohn's disease. Gastroenterology. 2004;126:1257-1269.

Targan SR, Hanauer SB, van Deventer SJ, et al. A short term study of chimeric monoclonal antibody CA2 to tumor necrosis factor alpha for Crohn's disease. N Engl J Med. 1997;337:1029-1035.

Ten Hove T, van Montfrans C, Peppelenbosch MP, et al. Infliximab treatment induces apoptosis of lamina propria T lymphocytes in Crohn's disease. Gut. 2002;50:206-211.

Travis SP, Stange EF, Lemann M, et al. European Crohn's and Colitis Organisation. European evidence-based consensus on the diagnosis and management of Crohn's disease: current management. Gut. 2006;55(Suppl. 1):i16-i35.

Van Assche G, Vermeire S, Rutgeerts P. Safety issues with biological therapies for inflammatory bowel disease. Curr Opin Gastroenterol. 2006;22:370-376.

Van den Brande JMH, Koehler TC, Zelinkova Z, et al. Prediction of antitumour necrosis factor clinical efficacy by real-time visualisation of apoptosis in patients with Crohn's disease. Gut. 2007;56:509-517.
Vermeire S, Noman M, Van Assche G, et al. Effectiveness of concomitant immunosuppressive therapy in suppressing the formation of antibodies to infliximab in Crohn's disease. Gut. 2007;56:1226-1231.

Vetterlein OM, Kopotsha T, Nesbitt AM, et al. Antibodies to infliximab in patients with Crohn's disease do not cross-react with certolizumab pegol. Gut. 2006;55(Suppl. V):A133. Abstract MON-G-261.

Vetterlein OM, Nesbitt AM, Stephens S. Antibodies to certolizumab pegol in patients with Crohn's disease do not cross-react with adalimumab, etanercept, or infliximab. Gastroenterology. 2007;132:4(Suppl. 2):A-556. Abstract T1784.

Weir AN, Nesbitt A, Chapman AP, Popplewell AG, Antoniw P, Lawson AD. Formatting antibody fragments to mediate specific therapeutic functions. Biochem Soc Trans. 2002;30:512-516.

Weir N, Athwal D, Brown D, et al. A new generation of high-affinity humanized pegylated Fab' fragment anti-tumor necrosis factor-a monoclonal antibodies. Therapy. 2006;3:535-545.

Winter TA, Wright J, Ghosh S, Jahnsen J, Innes A, Round P. Intravenous CDP870, a pegylated Fab' fragment of a humanized antitumor necrosis factor antibody, in patients with moderate to severe Crohn's disease: an exploratory study. Aliment Pharmacol Ther. 2004;20:1337-1346.

Winter TA, de Villiers WJS, Mardini HE. CDP870 in Crohn's disease: reconsidering endpoints. Inflamm Bowel Dis. 2006;12:249.

Zalipsky S. Functionalized polyethylene glycol for preparation of biologically relevant conjugates. Bioconjug Chem. 1995;6:150-165.

Correspondence: Professor G. Bianchi Porro, Chair of Gastroenterology, "L. Sacco" University Hospital, via G.B. Grassi 74, 20157 Milan, Italy or at gabriele.bianchiporro@unimi.it 